\title{
Ensayo sobre los «Factores de riesgo identificados en las sentencias dictadas en Portugal sobre los homicidios en el contexto conyugal»
}

Autora: Magíster en Criminología Shirley Gabriela Huanca Quillahuamán

Hace muy poco, culminé una maestría en criminología motivada por abordar las problemáticas sociales y realizar investigaciones, no solo desde lo cuantitativo, sino desde la amplitud de lo cualitativo, pues me abre a enriquecer la investigación e ir más allá de lo clásico entre los estudiantes de derecho que solemos valorar una situación, desde la rigidez de la interpretación jurídica.

Al igual que en el Perú, en Portugal no existe un artículo específico bajo la denominación de «homicidio conyugal», sin embargo, en ambas legislaciones, el homicidio cometido por un cónyuge en contra del otro puede ser punido como un 'homicidio agravado', o, en el caso de Perú, puede ser punido también como «feminicidio». El homicidio o tentativa de homicidio cometido por un cónyuge en contra de otro genera, además de una percepción de inseguridad que puede ser medible, una sensación de pérdida de confianza en la sociedad, resultando difícil aceptar que este tipo de crímenes se cometa entre personas que mantuvieron un vínculo afectivo de pareja.

En base a lo antes expresado, realicé un estudio intitulado Fatores de risco no cometimento de homicídio em contexto conjugal enunciados nas sentenças judiciais proferidas em Portugal, en la «Universidade do Porto-Portugal», para obtener el grado de magíster. Este estudio realizado - sobre los factores de riesgo identificados en las sentencias dictadas en Portugal—además de los homicidios en el contexto conyugal, fue desarrollado en base a un estudio previo: «Decisões judiciais em matéria de homicídios conjugais-estudo de sentencing». (Quintas, Souza e Leite, 2015).

Entre las principales conclusiones obtenidas en el estudio de los factores de riesgo destacan, que el género femenino fue la población que resultó más afectada, pues del total de sentencias estudiadas, se evidenció que un 90,5 \% de condenados fueron varones y un 90,5 \% de mujeres 
fueron las víctimas. Según las características sociodemográficas, la mayoría de condenados por este tipo de delitos fueron adultos con estado civil de casado, empleados con ocupaciones inestables, asimismo, se aplicaron instrumentos validados de evaluación de riesgo y se concluyó, que si se hubieran aplicado antes de acontecer los hechos, estos homicidios podrían haber sido evitados.

Finalmente, como un último aporte se podría mencionar que en Portugal, en el nivel de estadísticas realizan una distinción de los homicidios que se cometen en contexto conyugal frente a otros tipos de homicidios lo cual facilita la investigación en este campo en pro de aportes que disminuyan la incidencia de este tipo de delitos.

El tratamiento de los homicidios entre cónyuges merece especial relevancia en nuestra región y está íntimamente vinculado a la problemática de la violencia familiar en cualquiera de sus modalidades por lo que, se debe abordar desde el punto de vista de la prevención.

\section{BIBLIOGRAFÍA}

Quintas, Souza e Leite. (2015). Decisões judiciais em matéria de homicídios conjugais-Estudo de sentencing. Universidade do Porto. Porto: Facultade de Direito da Universidade do Porto. Obtenido de https://www.cig.gov.pt/wp-content/uploads/2015/07/Sum\%C3\%A1rioexecutivo-Decis\%C3\%B5es-judiciais-em-mat\%C3\%A9ria-de-homic\%C3\%ADdiosconjugais.pdf 